\title{
ABERTURA DA ESTRATÉGIA ANTE COMPLEXIDADE INSTITUCIONAL: O ESTABELECIMENTO DE REDES ORGANIZACIONAIS COMO UMA RESPOSTA ESTRATÉGICA POSSIVEL
}

\author{
MARINA ROZIN \\ Mestranda em Administração, Universidade Federal Do Paraná - UFPR, Brasil. \\ Professora-Tutora do Programa de Ensino a Distância, Universidade Positivo - UP, Brasil \\ marinarozinx@gmail.com \\ NATÁLIA RESE \\ Doutora em Administração, Universidade Federal do Paraná - UFPR, Brasil. \\ Docente do Programa de Pós-Graduação em Administração da Universidade Federal do Paraná - UFPR, Brasil. \\ natalia.rese@ufpr.br
}

\section{Resumo}

Esse trabalho tem por objetivo discutir respostas estratégicas adotadas pelas organizações expostas à complexidade institucional ocasionada pela pluralidade e conflito entre lógicas institucionais. O contexto selecionado como pano de fundo para compreender e discutir este fenômeno é o desafio promovido pelas parcerias estabelecidas entre o setor privado e a Organização das Nações Unidas (ONU) para alcance das metas estabelecidas pelos Objetivos do Desenvolvimento Sustentável (ODS). Neste contexto estão presentes duas lógicas que se configuram como plurais e potencialmente conflitantes e inserem a organização em um cenário de complexidade institucional: a lógica do mercado e a lógica do desenvolvimento humano e sustentável. Esta é a base do argumento deste ensaio teórico, propondo que, diante da complexidade institucional promovida pela pluralidade e conflito entre lógicas institucionais, as organizações se engajam em redes de colaboração e abrem sua estratégia para o compartilhamento de práticas em busca de cumprir com compromissos por elas assumidos.

Palavras-chave: lógicas institucionais, complexidade, redes, estratégia aberta. 


\title{
STRATEGY OPENING BEFORE INSTITUTIONAL COMPLEXITY: THE ESTABLISHMENT OF ORGANIZATIONAL NETWORIKS AS A POSSIBLE STRATEGIC RESPONSE
}

\begin{abstract}
This paper aims to discuss the strategic responses adopted by organizations exposed to the institutional complexity caused by the plurality and conflict between institutional logics. The context selected as the background for understanding and discussing this phenomenon is the challenge promoted by the partnerships established between the private sector and the United Nations to achieve the goals set by the Sustainable Development Goals. In this context there are two logics that are configured as plural and potentially conflicting and insert the organization in a scenario of institutional complexity: the logic of the market and the logic of human and sustainable development. This is the basis of the argument of this theoretical essay, proposing that, in view of the institutional complexity promoted by the plurality and conflict between institutional logics, organizations engage in collaborative networks and open their strategy for sharing practices in pursuit of commitments assumed.
\end{abstract}

Keywords: institutional logics, complexity, networks, open strategy.

\section{APERTURA DE LA ESTRATEGIA ANTE LA COMPLEJIDAD INSTITUCIONAL: EL ESTABLECIMIENTO DE REDES ORGANIZACIONALES COMO UNA RESPUESTA ESTRATÉGICA POSIBLE}

\begin{abstract}
Resumen
Este trabajo tiene por objetivo discutir respuestas estratégicas adoptadas por las organizaciones expuestas a la complejidad institucional ocasionada por la pluralidad y el conflicto entre lógicas institucionales. El contexto seleccionado como contexto para comprender y discutir este fenómeno es el desafío promovido por las vínculos establecidos entre el sector privado y la Organización de las Naciones Unidas para alcanzar las metas establecidas por los Objetivos del Desarrollo Sustentable (ODS). En este contexto están presentes dos lógicas que se configuran como plurales y potencialmente conflictivas e inserta la organización en un escenario de complejidad institucional: la lógica del mercado y la lógica del desarrollo humano y sustentable. Esta es la base del argumento de este ensayo teórico, proponiendo que ante la complejidad institucional promovida por la pluralidad y conflicto entre lógicas institucionales, las organizaciones se comprometen en redes de colaboración y abren su estrategia para compartir prácticas para cumplir sus compromisos.
\end{abstract}

Palabras clave: lógicas institucionales, complejidad, redes, estrategia abierta.

OS, Organizações e Sustentabilidade, 7(1), p. 16-31, Londrina, PR, jan./jun. 2019.

ISSN 2318-9223, http://www.uel.br/revistas/uel/index.php/ros/issue/view/1535/showToc 


\section{INTRODUÇÃO}

Este trabalho tem por objetivo discutir respostas estratégicas adotadas pelas organizações expostas à complexidade institucional ocasionada pela pluralidade e conflito entre lógicas institucionais. Meyer e Höllerer (2016) destacam que os estudos atuais estão direcionados para a observação de organizações expostas à multiplicidade de expectativas organizacionais, originadas pela pluralidade institucional e pela complexidade institucional.

Dunn e Jones (2010, apud Greenwood, Raynard, Kodeih, Micellota, \& Lounsbury 2011) apresentam 0 pluralismo institucional como sendo a existência de grupos com interesses distintos que criam uma dinâmica de tensões e contradições. A existência do pluralismo, especialmente pela dinâmica de tensões por ele ocasionada, insere a organização em um ambiente complexo, que podemos tomar como institucional, ao considerar que cada grupo possui interesses distintos, pois representa seu próprio conjunto de valores desenvolvidos pela interação de aspectos culturais e materiais (Thornton \& Ocasio, 2008).

O contexto selecionado como pano de fundo para compreender e discutir este fenômeno é o desafio promovido pelas parcerias estabelecidas entre o setor privado e a Organização das Nações Unidas (ONU) para alcance das metas estabelecidas pela agenda 2030 para os Objetivos do Desenvolvimento Sustentável (ODS). Neste contexto estão presentes duas lógicas que, por suas premissas, se configuram como plurais e potencialmente conflitantes e inserem a organização em um cenário de complexidade institucional: a lógica do mercado - como premissa da realidade organizacional - e a lógica do desenvolvimento humano e sustentável - base das metas estabelecidas pelos ODS.

Isso posto, o objetivo deste trabalho é discutir como as organizações lidam com as condições promovidas pela complexidade institucional. Para isso, tem como base a ampliação do argumento de Oliver (1991) de que as organizações buscam apresentar respostas estratégicas para a adequação isomórfica de práticas e estruturas que atendam às pressões institucionais. Neste trabalho serão discutidas respostas estratégicas em potencial para o enfrentamento do fenômeno da complexidade institucional.

Nos últimos anos, os estudos do tema apresentaram diversas respostas potenciais das organizações para o cenário de complexidade institucional (Vermeulen, Zietsma \& Langley, 2014), em uma chamada especial para o periódico Strategic Organization, afirmam que há diversas vias de estudo para a discussão do tema. Ainda afirmam que, em linhas gerais, os estudos atuais apresentam quatro abordagens principais: (1) descrição ou prescrição das estratégias empregadas pelas organizações face à multiplicidade de lógicas institucionais, (2) foco nas estratégias e práticas gerenciais das chamadas "organizações híbridas" - organizações que em sua essência estão sujeitas à pluralidade de lógicas institucionais (Batillana \& Dorado, 2010), (3) observação dos aspectos emocionais e cognitivos presentes na complexidade institucional e, por fim, (4) exploração do fenômeno da complexidade em campo, observando como a agência coletiva pode moldar as lógicas institucionais.

Este trabalho seguirá a primeira abordagem, focada na compreensão de como as organizações respondem a múltiplas lógicas institucionais. À essa chamada especial, os artigos focados na primeira abordagem apresentaram trabalhos relacionados à hibridez estrutural (Raynard, 2016), à escolha entre acoplamento e desacoplamento de práticas (Misangyi, 2016) e à ambiguidade e técnicas discursivas de neutralização do uso da imagem.

Diversamente às respostas apontadas, este ensaio teórico argumenta que, diante de desafios complexos e ambíguos, as organizações que têm como pressuposto a lógica do mercado se dispõem a abrir sua estratégia organizacional, compartilhando informações e práticas com outras

OS, Organizações e Sustentabilidade, 7(1), p. 16-31, Londrina, PR, jan./jun. 2019. 
organizações por meio de uma rede de colaboração que busca cumprir com objetivos e desafios semelhantes.

Para a estruturação do argumento, o presente trabalho apresentará o referencial teórico, que abarca as teorias de base para discussão: lógicas institucionais e complexidade institucional, redes interorganizacionais e estratégia aberta. Na sequência será discutido um contexto de análise possível para esse argumento, a partir da adoção dos Objetivos de Desenvolvimento Sustentável (ODS) pelas organizações participantes da Rede Brasil do Pacto Global. O artigo finalizará apresentando as sugestões para futuras agendas de pesquisa dentro do tema.

\section{REVISÃO TEÓRICA}

\section{LóGICAS INSTITUCIONAIS E COMPLEXIDADE INSTITUCIONAL}

As Lógicas Institucionais, enquanto temática do Institucionalismo Organizacional, apresentam-se como uma abordagem alternativa para a ampliação da perspectiva. Em estudos iniciados a partir da década de 90, essa abordagem surge para desenvolver explicações mais amplas a respeito do conteúdo e o propósito das organizações, refutando conceitos como o isomorfismo com o ambiente amplo e de forma duradoura, posicionando uma visão na variedade de lógicas institucionais proporcionada pelos diferentes contextos nos quais as organizações se encontram. (Thornton \& Ocasio, 2008).

O conceito de lógicas institucionais foi apresentado por Friedland e Alford (1991) para descrever as práticas e crenças contraditórias inerentes às instituições da sociedade moderna, tais como o capitalismo, o mercado, a democracia, o estado, a família e a religião. A partir de então, diversos autores contribuíram para o desenvolvimento da perspectiva, agregando a noção de que essas práticas e crenças são socialmente construídas pelos indivíduos e pelas organizações, como forma de reproduzir e dar significado às suas experiências (Thornton, Ocasio, \& Lounsbury, 2012). Desta forma, ao mesmo tempo em que indivíduos e organizações são capazes de influenciar e modificar as lógicas presentes nas instituições, eles também possuem influência sobre suas ações e decisões (Thornton \& Ocasio, 2008).

Observa-se então que a formação de uma lógica institucional prevê a relação recursiva entre o sujeito - indivíduo ou organização - e as práticas por ele adotadas e modificadas. Friedland, Mohr, Roose e Gardinali (2014) acrescentam o objeto como aquilo que confere substancialidade e ordenamento às práticas. Esses três elementos - sujeito, prática e objeto - recursivamente construídos, organizam e desenvolvem a lógica institucional ao longo do tempo (Friedland et al., 2014).

Para Thornton e Ocasio (2008), o conhecimento produzido a respeito das lógicas institucionais apresenta pressupostos comuns, que podem, em sua maioria, ser sintetizados em cinco princípios. 0 primeiro deles, o embedded agency, apresenta as decisões como resultado da interação entre a agência do ator (indivíduo ou organização) e a estrutura institucional, sendo seus interesses limitados pela lógica institucional em que está imerso, proporcionando agência parcialmente autônoma por parte dos indivíduos e da organização (Friedland \& Alford, 1991).

O segundo princípio, proposto por Friedland e Alford (1991), afirma que a diversidade de práticas e crenças configura a sociedade como um sistema inter-institucional, em que cada setor representa suas expectativas para as relações e comportamentos, para os indivíduos e para as organizações (Thornton \& Ocasio, 2008). Estando as organizações inseridas nesse sistema e se relacionando com diversos setores simultaneamente, estão, portanto, sujeitas às contradições existentes entre lógicas institucionais distintas.

0 terceiro princípio assume que cada um desses setores sociais, bem como suas lógicas, possuem características culturais e materiais específicas que desenvolvem e promovem mudanças que

OS, Organizações e Sustentabilidade, 7(1), p. 16-31, Londrina, PR, jan./jun. 2019.

ISSN 2318-9223, http://www.uel.br/revistas/uel/index.php/ros/issue/view/1535/showToc 
moldam as lógicas institucionais (Thornton \& Ocasio, 2008). Desta forma, todas as lógicas estão sujeitas, em maior ou menor parcela, aos aspectos culturais e materiais das instituições da sociedade de que fazem parte. Isso significa que nenhuma lógica institucional assume um tipo puro e todas possuem aspecto inter-relacionado, que, dependendo das configurações individuais, pode conflitar ou se conformar ao se deparar com outra lógica.

0 quarto princípio proposto por Thornton e Ocasio (2008) assume que as lógicas institucionais podem se desenvolver não somente pelos efeitos da sociedade nos indivíduos e nas organizações, mas também por múltiplos níveis de interação, tais como os mercados, as comunidades geográficas e as redes interorganizacionais.

Por fim, o quinto princípio, a contingência histórica busca compreender como os ambientes podem afetar o comportamento dos indivíduos e das organizações. A forma como cada uma das instituições se desenvolve junto com a história da sociedade no tempo determina qual lógica terá mais ênfase em cada época da sociedade (Thornton \& Ocasio, 2008).

Além da conceituação proposta por Friedland e Alford (1991) e dos pressupostos apontados por Thornton e Ocasio (2008), os estudos do tema avançaram trazendo diversos conceitos, tais como pluralidade e complexidade provocada pelas lógicas institucionais.

De acordo com Meyer e Höllerer (2016), a sociedade moderna apresenta características que apontam sua forte congruência com princípios das lógicas institucionais. Nesse contexto de uma sociedade plural e diversa em valores sistemicamente conectados, o pluralismo institucional torna-se norma social.

O conceito de pluralismo, inserido por Dunn e Jones (2010, apud Greenwood et al., 2011) é caracterizado pela existência de grupos com interesses distintos que criam a dinâmica de tensões e contradições. A existência do pluralismo, especialmente pela dinâmica de tensões por ele ocasionada, insere a organização em um ambiente complexo, que podemos tomar como institucional ao considerar que cada grupo possui interesses distintos, pois representa seu próprio conjunto de valores desenvolvidos pela interação de aspectos culturais e matérias (Thornton \& Ocasio, 2008).

A influência de um ambiente complexo foi tratada por Hatch e Ehrlich (1993, p. 505, tradução livre), em que os autores afirmam que "... quando os ambientes são complexos e mutáveis, há condição para contradição, incongruência, incoerência e reconhecimento do paradoxo e ambiguidade entre organizações". Essa afirmação é refinada por Greenwood et al., que traz à tona a complexidade não como resultado do ambiente de forma ampla, mas da tensão entre as instituições e suas lógicas. 0 autor afirma que as organizações enfrentam complexidade institucional sempre que enfrentam demandas incompativeis, vindas de diversas lógicas institucionais (Greenwood et al., 2011).

De acordo com Carrol (2015), complexidade e mudança são fatores promotores de incerteza e ambiguidade, sendo a incerteza a dúvida do conhecimento, como informações e probabilidades de ocorrência, e a ambiguidade como a incapacidade de compreensão de um evento, talvez por este ser indefinido. Lerner (1978) insere ambos os fatores dentro dos conceitos de incerteza, pois, para 0 autor, tanto a falta de conhecimento quanto a falta de confiança no que se conhece podem ser consideradas incertezas. De qualquer forma, Lerner (1978) destaca que, no mundo real, ambas são sobrepostas e entrelaçadas nas situações de conflito.

\section{Redes Organizacionais}

Segundo Emirbayer e Goodwin (1994, p. 5, tradução própria), “ ... o estudo das redes não trata de uma teoria formal distinta por leis, proposições ou correlações, mas de uma ampla estratégia que

OS, Organizações e Sustentabilidade, 7(1), p. 16-31, Londrina, PR, jan./jun. 2019. 
investiga as estruturas sociais", sendo as relações em rede um modelo alternativo de análise da sociedade.

As redes de relações em organizações, de acordo com Saint-Charles e Mongeau (2008), podem ser entendidas como padrões formados por relações formais e informais, em relações instrumentais e expressivas, sendo as relações instrumentais relacionadas às situações de trabalho e as expressivas referentes ao envolvimento emocional.

Para Scott e Davis (2007), essas relações presentes na rede são representadas por laços entre participantes em relações intraorganizacionais ou por laços entre organizações presentes nas relações interorganizacionais. Para o desenvolvimento do argumento, este artigo tratará da segunda vertente de relações, desenvolvidas para intercâmbio de conhecimento, aprendizagem e estabelecimento de alianças e parcerias estratégicas com base na colaboração.

A rede em forma de aliança ou parceria estratégica atrai organizações que buscam superar seus pontos fracos e combinar seus pontos fortes de maneira colaborativa (Powell, 1990). Neste sentido, Powell (1990) destaca que os pilares de sustentação de uma rede de sucesso estão na complementariedade de forças e fraquezas entre os integrantes e na acomodação de cada membro - seu papel assumido - dentro dos interesses coletivos.

Outra premissa para o sucesso da organização em rede apontada por Powell (1990) é a confiança nas relações entre membros. Para o autor, a presença da confiança confere vantagem ao formato de relações em rede, pois esta característica se mostra mais eficaz na redução da complexidade presente na realidade organizacional do que previsão, autoridade ou negociação.

Considerando o ambiente de competição em que as organizações estão inseridas, em que capacidades e recursos configuram uma vantagem competitiva (Barney, 1991), questiona-se: qual a motivação para o engajamento das organizações em redes de cooperação e intercâmbio de conhecimento?

A vertente do construcionismo estruturalista prevê que a afinidade estrutural - configuração da rede, quais são os membros e papéis - possibilita a afinidade de atitude e o voluntarismo em participar da rede (Emirbayer \& Godwinn, 1994). Ademais, Powell (1990) afirma que as organizações que se engajam em relações sociais em rede compreendem que os limites organizacionais configuram limites de conhecimento e informação e que há desafios a alcançar que vão além da capacidade individual da organização. Desta forma, o engajamento das organizações em redes interorganizacionais se torna vantajoso à medida que o nivel de incerteza e a necessidade de maior conhecimento sobre o ambiente aumenta (Powell, 1990).

Uzzi e Lancaster (2014) abordam a incerteza quanto ao conhecimento pela perspectiva do risco ocasionado pela necessidade de aprender para obtê-lo. Os autores afirmam que a transferência de conhecimento e processos de aprendizagem, por meio de redes e canais, reduz os riscos associado à aprendizagem para as organizações. Concluem afirmando que a aprendizagem ocorre não somente na cognição, mas também na relação entre atores e que a aprendizagem social - em detrimento da individual - ajuda a resolver problemas relacionados com a transferência de conhecimento e aprendizagem.

Em complemento, Saint-Charles e Mongeau (2008) apontam que, em demandas relacionadas a situações de incerteza, em que são necessárias informações e expertise para troca de experiências e realização tarefas, há a necessidade de apoio técnico ou informações encontradas nas relações instrumentais - o tipo de relação apresentada pelo objeto de estudo deste artigo.

O engajamento voluntário das organizações em rede dependerá da afinidade estrutural destas para com a outra (Emirbayer \& Godwinn, 1994). Granovetter (2007) destaca a preferência dominante em

OS, Organizações e Sustentabilidade, 7(1), p. 16-31, Londrina, PR, jan./jun. 2019.

ISSN 2318-9223, http://www.uel.br/revistas/uel/index.php/ros/issue/view/1535/showToc 
fazer transações com indivíduos de reputação conhecida, pois poucos estão realmente dispostos a confiar na moralidade generalizada ou nos dispositivos institucionais para evitar problemas.

Powell (1990) afirma que o engajamento dos participantes em redes de trocas e parcerias é motivado pela busca da redução da incerteza, o acesso rápido à informação, a confiabilidade e capacidade de resposta. A transferência de conhecimento por meio das redes reduz o risco individual, favorece a aprendizagem e, consequentemente, reduz a complexidade imposta pelo contexto. Corroborando o argumento, Surowiecki apud Stieger, Martzler, Chatterjee, \& Ladstaetter-Fussenegger (2012, p. 46, tradução livre) argumenta que “... grandes grupos de pessoas são mais espertos que uma pequena elite, por mais brilhante, capaz de resolver problemas, inovadora, sábia e boa em tomar decisões seja". Desta forma, o engajamento em rede possibilita a redução da incerteza, o acesso à informação, a confiabilidade e melhor desempenho na resolução de problemas.

O uso da rede interorganizacional ainda apresenta outros aspectos favoráveis para as organizações lidarem com a complexidade originada pelas lógicas institucionais. Destaca-se a possibilidade de aumento da agência por parte do ator social em relação à lógica institucional em que está imerso. De acordo com White (1992 apud Emirbayer \& Goodwin, 1994, p. 28) "... a agência é a face dinâmica de redes, agência entendida não apenas como um subproduto de controle, mas também como forma de revolucionar instituições e iniciar nova ação". Assim, a organização é capaz de assumir maior controle sobre suas decisões, práticas e ações, pois os efeitos da imersão social em uma lógica dominante são minimizados pela difusão de suas relações sociais.

A rede pode ser um mecanismo de resposta para a complexidade ocasionada pelo conflito entre diversas lógicas institucionais, pois, como lembram Emirbayer e Goodwin (1994), as redes são uma estrutura social. Isso implica que nela estão presentes as lógicas institucionais da sociedade e, portanto, carregam consigo a carga cultural e material das diversas lógicas presentes nos seus membros. Destarte, "... diferentes tipos de grupos, relações e instituições que supostamente organizam ou estruturam os processos sociais podem ser entendidos como ou transformados em redes". (Emirbayer \& Goodwin, 1994, p. 9).

Todavia, as redes não configuram por si só a resposta à complexidade organizacional. Burt (2004) ressalta que redes não agem, mas são contextos para a ação de indivíduos e organizações. Considera-se que a abertura da estratégia se transforma na ação necessária para completar a resposta à complexidade

\section{ABERTURA dA EstratÉGIA}

A noção de abertura da estratégia é recente no campo dos estudos de estratégia e surge da combinação entre construção social advinda da Estratégia como Prática Social e da Inovação Aberta, perspectiva do campo da inovação. Foi articulada pela primeira vez por Chesbrough e Appleyard (2007) e teve sua primeira tentativa de definição comum cunhada pelo recente trabalho de Tavakoli, Schlagwein e Schoder (2015). Desde então, autores como Whittington e Yakis-Douglas (2011), Haefliger, Monteiro, Foray e Krogh (2011), Gast e Zanini (2012) e Dobusch e Kapeller (2013) trabalham para o desenvolvimento da perspectiva.

Enquanto conceito, Stieger, Martzler, Chatterjee e Ladstaetter-Fussenegger (2012) propõem que a estratégia aberta é um processo de interação social baseado no compartilhamento de crenças e entendimentos por parte dos membros da organização. Whittington e Yakis-Douglas (2011), desenvolvendo um conceito teórico da abertura da estratégia, afirmam que este processo possui dois pressupostos básicos: transparência e inclusão.

A transparência compreende que tanto o processo de formulação quanto o resultado deste devem ser comunicados a todos os envolvidos, desta forma, se torna pressuposto para o segundo 
pressuposto. A inclusão prevê que todos membros devem ser envolvidos no processo de fazer a estratégia - strategizing - em um trabalho colaborativo, permeada pelo compartilhamento entre pares e que envolve tanto colaboradores internos quanto externos da organização.

Tavakoli, Schlagwein e Schoder (2015) sugerem compreender o fenômeno da abertura da estratégia como a abertura de uma ou várias atividades do processo de formação da estratégia. Matzler (2014 apud Morton, Wilson, \& Cooke, 2015) aponta que abrir a estratégia para uma gama maior de atores - internos ou externos - agrega valor a esta por permitir o alcance da organização a fontes de conhecimento anteriormente subvalorizadas. Desta forma, a estratégia aberta pode ser utilizada como um dispositivo para a colaboração organizacional e compartilhamento de conhecimento interno e externo (Morton, Wilson, \& Cooke, 2015).

A aproximação teórica entre a estratégia aberta e as lógicas institucionais é possivel pelo compartilhamento de pressupostos. Assim como as lógicas institucionais, a estratégia aberta assume que a interação social, por meio do compartilhamento de crenças e práticas, constrói a estratégia e a realidade do indivíduo, bem como as próprias crenças e práticas nas quais realiza sua ação.

Para ambas as perspectivas, todos os sujeitos ou atores organizacionais são componentes ativos na criação de sua realidade e no processo de construção da estratégia e ao longo do tempo mudam sua realidade ao mesmo tempo em que são influenciados por ela. Desta forma, a agência do sujeito - ou da organização - mesmo que limitada pelas lógicas institucionais relativas ao contexto em que está inserido, ainda o pertence e permite sua decisão e ação perante o cenário complexo em que se encontra.

A abertura da estratégia configura associação adequada para a ação social em rede por dividir noções como a colaboração, envolvimento de todos os atores no processo de construção da estratégia e, principalmente, o compartilhamento de informações entre atores internos e externos à organização, aspectos determinantes na redução da incerteza e complexidade institucional. A qualidade "em aberto" de redes (Powell, 1990) adicionada ao fazer estratégico compartilhado da estratégia configura resposta útil quando os recursos são variáveis e o ambiente incerto.

A estratégia aberta, por meio do processo de interação social que abarca o compartilhamento de crenças e entendimentos, favorece a participação de diversos atores, tanto internos quanto externos, no processo de fazer a estratégia - strategizing, promovendo a transparência não somente do resultado, mas das informações relativas ao processo, favorecendo, desta forma, 0 compartilhamento de práticas e conhecimento. Nesse sentido, Carrol (2015) afirma que as estratégias de maior sucesso para lidar com a ambiguidade promovem o engajamento de atores internos e externos da organização como forma de promover diversas perspectivas e sugestões inovadoras que contribuam para a aprendizagem.

\title{
UM CONTEXTO PARA ANÁLISE DA RELAÇÃO PROPOSTA: A REDE EMPRESARIAL DO PACTO GLOBAL
}

\begin{abstract}
“Executivos em todas as áreas da sociedade são, no que diz respeito ao seu papel e poder, parte da elite de quem é esperado que reconheça melhor e mais cedo que outros que seus objetivos e comportamentos sejam apropriados para a salvaguarda do futuro. 0 fato de que a gestão empresarial assume responsabilidade social implica fazer grandes esforços não só para prosseguir com os interesses da empresa, mas também fazer o que é melhor para a sociedade em geral." (Ulrich, 1980 apud Meyer \& Höllerer, 2016, p. 5, tradução livre).
\end{abstract}

Observando a relevância das organizações do setor privado no cenário global, a Organização das Nações Unidas (ONU) destaca a importância do comprometimento delas, juntamente com outros atores, como países, governos e a sociedade, em estabelecer a paz e o desenvolvimento mundial,

OS, Organizações e Sustentabilidade, 7(1), p. 16-31, Londrina, PR, jan./jun. 2019.

ISSN 2318-9223, http://www.uel.br/revistas/uel/index.php/ros/issue/view/1535/showToc 
bem como participar ativamente do alcance da agenda de Objetivos do Desenvolvimento Sustentável (Organização das Nações Unidas, n.d.).

Sendo a ONU um dos organismos de grande influência e articulação entre nações em prol do desenvolvimento e paz mundial, os Objetivos do Desenvolvimento Sustentável constituem uma agenda de pauta, concordância e compromisso global e as organizações do setor privado figuram como um agente fundamental para o alcance das metas globalmente assumidas por 192 nações (Organização das Nações Unidas, n.d.); nota-se que o engajamento dessas organizações especialmente as grandes corporações mundiais - configura fator relevante para a manutenção de suas relações de mercado, o que as pressiona para a incorporação de práticas de responsabilidade social corporativa.

Como forma de mobilizar o setor privado para a adoção de práticas consonantes com os valores universais e que contribuam para o alcance das metas estabelecidas para o desenvolvimento mundial, a ONU desenvolveu o Pacto Global (PG), que consiste em uma declaração de apoio e compromisso por parte das organizações aos dez princípios universais relacionados aos direitos humanos, relações de trabalho, meio ambiente e combate à corrupção (Programa das Nações Unidas para o Desenvolvimento, n.d.).

Do lançamento dos Objetivos do Milênio em 2000 até o ano de 2003, houve baixa aderência por parte das organizações em assumir compromissos junto à ONU. Como forma de impulsionar a adoção da cidadania empresarial, as organizações brasileiras signatárias formaram em 2003 a denominada Rede Brasileira Empresarial do Pacto Global e estabeleceram um comitê representativo com o objetivo de fortalecer a agenda da responsabilidade social corporativa.

A partir deste momento, a Rede Brasileira passou a ganhar expressividade dentro do movimento nacional e internacional em prol do desenvolvimento sustentável e definiu objetivos específicos de sua missão, como o apoio às empresas brasileiras para implementação dos princípios, troca de experiências e aprendizado e promoção do vínculo entre os princípios do PG e os ODS (Pacto Global, n.d.). Atualmente, a Rede Brasileira representa a "3a maior rede local" (Rede Brasil do Pacto Global, n.d.), com 752 membros brasileiros, dos quais 109 são signatários ativos, conforme dados disponiveis no site das Nações Unidas - Pacto Global (UN - Global Compact, n.d.). A atual Diretoria da Rede é composta pela presidência do Itaú-Unibanco (Serviços Financeiros) e pelas empresas Enel Distribuição (Eletricidade - Serviços de Suporte), CFPL Energia S.A. (Eletricidade), B3 - Brasil Bolsa Balcão (Serviços Financeiros) e BASF SE (Empresa do ramo Químico). O Comitê Gestor da Rede Brasil do Pacto Global apresenta a composição apresentada a seguir: 


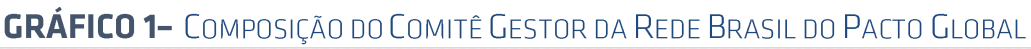

\section{Composição do Comitê Gestor da Rede Brasil do Pacto Global}

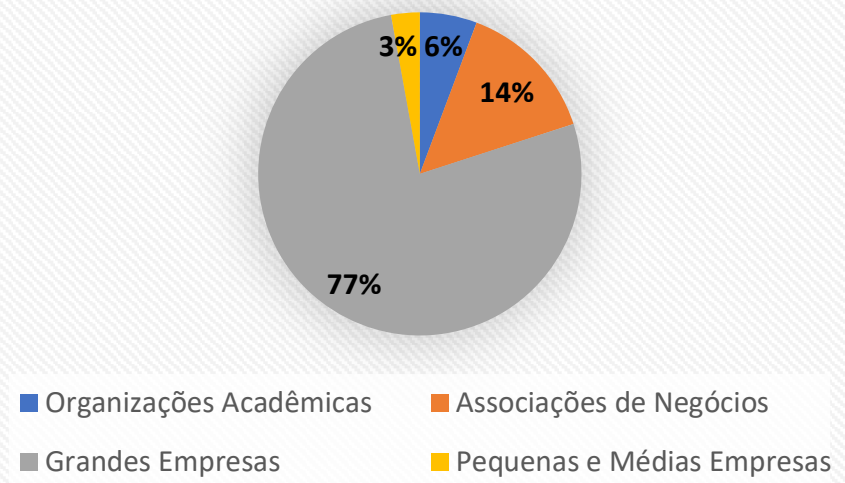

Fonte: Elaborado a partir de dados disponíveis no site das Nações Unidas - Pacto Global (UN - Global Compact, 2018 https://www.unglobalcompact.org)

Ressalta-se que, das organizações que compõem a categoria "Grandes Empresas", 70\% correspondem aos setores da indústria (química, eletrônica, linha branca, alimentos e farmacêutica), serviços financeiros, energia e eletricidade, reproduzindo a configuração apresentada na Diretoria da Rede supra-apresentada.

Esta composição da Diretoria da Rede simétrica à Composição do Comitê Gestor evidencia um tendência da orientação das práticas discutidas na Rede pela lógica das organizações de grande porte, principalmente do setor industrial e financeiro, tendo em vista que, se o argumento teórico deste ensaio for válido, a predisposição para a participação de uma rede e a abertura da estratégia das organizações ocorrem quando ela se encontra face a uma pluralidade de lógicas com as quais não consegue lidar. A partir disso, se a centralidade de poder da rede está nas mãos de organizações que são direcionados por uma determinada lógica (no caso, a lógica de negócios), é adequado supor que as práticas adotadas seguirão a lógica institucional predominante entre os membros centrais.

Não obstante, dos 752 membros e dos 109 signatários ativos da Rede Brasil do Pacto Global, observase a seguinte composição:

TABELA 1 - Membros e SignatÁRIOS dA Rede Brasil do PACto Global

\begin{tabular}{|c|c|c|}
\hline Tipo de Organização & Número de Membros & Número de Signatárias \\
\hline Organizações Acadêmicas & 19 & \\
\hline Associações de Negócios & 55 & \\
\hline Cidades/Municípios & 28 & 47 \\
\hline Grandes Empresas & 263 & \\
\hline Fundações & 9 & 1 \\
\hline Organizações Sindicais & 5 & 61 \\
\hline ONCs & 92 & 109 \\
\hline Organizações do Setor Público & 14 & \\
\hline Pequenas e Médias Empresas & 267 & \\
\hline TOTAL & 752 & \\
\hline
\end{tabular}

Fonte: Elaborado a partir de dados disponíveis no site das Nações Unidas - Pacto Clobal (UN - Clobal Compact, 2018 https://www.unglobalcompact.org)

Diante da Tabela 1, percebe-se que 78\% das organizações participantes (Associações de Negócios, Grandes Empresas, Pequenas e Médias Empresas) possuem suas atividades orientadas predominantemente pela lógica de negócios. Dessa forma, percebe-se que a lógica da responsabilidade social e da sustentabilidade são, em princípio, dissonantes da lógica que orienta a

OS, Organizações e Sustentabilidade, 7(1), p. 16-31, Londrina, PR, jan./jun. 2019.

ISSN 2318-9223, http://www.uel.br/revistas/uel/index.php/ros/issue/view/1535/showToc 
grande maioria de suas atividades. Se for assim, essas organizações estão imersas em um contexto de pluralidade de lógicas que as coloca face ao dilema de qual lógica seguir, ou ainda, como conciliar lógicas dissonantes. Assim, é compreensivel, sob o argumento deste ensaio teórico, a disposição dessas organizações engajarem-se em uma rede e disporem-se a dialogar e criar práticas conjuntas para lidar com essas situações. Isso explica também a composição da rede com uma diversidade de organizações.

O que chama atenção, porém, é a contraposição da composição dos membros e da composição da Diretoria e do Comitê Gestor que, claramente, apresentam uma homogeneidade em relação à orientação da lógica de negócios. Se isso efetivamente ocorrer no âmbito da Rede, pode evidenciar o caminho da adoção cerimonial de práticas relacionadas aos aspectos da Responsabilidade Social e da Sustentabilidade.

Entenda-se que a discussão acima apresentada é um contexto para se pensar a problemática teórica apresentada neste artigo. Todos os aspectos apontados em linha de análise evidenciam uma tendência que pode apresentar caminhos de estudos futuros.

\section{ANÁLISE E DISCUSSÃO}

Ao assumir o compromisso com os princípios da ONU por meio do Pacto Global, será exigida da organização a habilidade de gestão para entender e responder a objetivos e demandas diversas, impostas por grupos de interesse com que organização se relaciona (Nasi, 1995 apud Thomasson, 2009). A organização então se depara com o desafio de responder às demandas sociais deste novo grupo de interesse, baseado em uma lógica social de desenvolvimento humano e sustentável que, por vezes, não possui consonância com a razão de ser ou negócio da organização.

As organizações do setor privado surgem e se estabelecem dentro de uma lógica principal - a lógica de mercado (ou lógica de negócios). Essa lógica traz consigo crenças, práticas e valores vindos da instituição do qual seu setor social faz parte, formadas historicamente pela influência de aspectos culturais e materiais distintos e, além disso, limitam o poder de agência do ator social, justamente por estar imerso nesta lógica (Thornton \& Ocasio, 2008).

A existência de duas lógicas distintas que possuem conflito de interesses e expectativas claro insere as organizações, que assumem - ou desejam assumir - compromissos e desejam estabelecer práticas que contribuam para os ODS, em um cenário de complexidade (Greenwood et al., 2011). A existência da complexidade é considerada um fator de incerteza, que pode ser originada pela falta de conhecimento por parte das organizações no que se refere à informações, práticas e ações que, de fato, sejam relevantes para os ODS ou pela incerteza no que se refere a saber se será adequado ou não para a organização pôr em prática seu conhecimento - considerando custos, imagem e o interesse de outros grupos (Carrol, 2015).

Observa-se que nos três primeiros anos do Pacto Global, mesmo com ações voltadas para o engajamento das empresas por meio de agentes como o Instituto Ethos, houve baixa adesão por parte das organizações e que este cenário apenas mudou a partir do momento em que a PNUD/ONU estabeleceu uma rede entre as organizações participantes para apoiar a implementação de práticas, trocar conhecimentos e aprendizados sobre os princípios do PG.

O engajamento voluntário das organizações em rede dependerá da afinidade estrutural destas para com a outra (Emirbayer \& Godwinn, 1994). No contexto analisado, observa-se que as organizações presentes na rede compartilham características institucionais e os mesmos desafios, sendo muitas delas organizações conhecidas e consolidadas no mercado nacional e mundial. Granovetter (2007) destaca, como já mencionado, a preferência dominante em fazer transações com indivíduos de reputação conhecida, pois poucos estão realmente dispostos a confiar na moralidade generalizada

OS, Organizações e Sustentabilidade, 7(1), p. 16-31, Londrina, PR, jan./jun. 2019.

ISSN 2318-9223, http://www.uel.br/revistas/uel/index.php/ros/issue/view/1535/showToc 
ou nos dispositivos institucionais para evitar problemas. Assim sendo, a confiança produzida pela presença de organizações reconhecidas e que possuem afinidade com as demais pode ter sido um fator determinante para o sucesso da Rede Empresarial Brasileira nos anos que se seguiram.

Powell (1990) afirma que o engajamento dos participantes em redes de trocas e parcerias é motivado pela busca da redução da incerteza, o acesso rápido à informação, confiabilidade e capacidade de resposta. A transferência de conhecimento por meio das redes reduz risco individual, favorece a aprendizagem e, consequentemente, reduz a complexidade imposta pelo contexto. Desta forma, o engajamento em rede possibilita a redução da incerteza, acesso à informação, confiabilidade e melhor desempenho na resolução de problemas.

O engajamento em redes ainda apresenta outros aspectos favoráveis para as organizações lidarem com complexidade originada pelas lógicas institucionais. Destaca-se a possibilidade de aumento da agência por parte do ator social em relação à lógica institucional em que está imerso.

De acordo com White (1992 apud Emirbayer \& Coodwin, 1994 p. 28) “... a agência é a face dinâmica de redes, agência entendida não apenas como um subproduto de controle, mas também como forma de revolucionar instituições e iniciar nova ação". Assim, a organização é capaz de assumir maior controle sobre suas decisões, práticas e ações, pois os efeitos da imersão social em uma lógica dominante são minimizados pela difusão de suas relações sociais.

A rede pode ser um mecanismo de resposta para a complexidade ocasionada pelo conflito entre diversas lógicas institucionais, pois, como lembram Emirbayer e Coodwin (1994), as redes são uma estrutura social, nela estão presentes as lógicas institucionais da sociedade e, portanto, carregam consigo a carga cultural e material das diversas lógicas presentes nos seus membros. Destarte, "... diferentes tipos de grupos, relações e instituições que supostamente organizam ou estruturam os processos sociais podem ser entendidos em ou transformados em redes" (Emirbayer \& Goodwin, 1994, p. 9).

Todavia, as redes não configuram por si só a resposta à complexidade organizacional. Burt (2004) ressalta que redes não agem, mas sim, são contextos para a ação de indivíduos e organizações. Assim, argumenta-se aqui, a abertura da estratégia se transforma na ação necessária para completar a resposta à complexidade.

A estratégia como prática configura associação adequada para a ação social em rede por dividir noções como a colaboração, envolvimento de todos os atores no processo de construção da estratégia e, principalmente, o compartilhamento de informações entre atores internos e externos à organização, aspectos determinantes na redução da incerteza e complexidade institucional. A qualidade "em aberto" de redes (Powell, 1990) adicionada ao fazer estratégico compartilhado da estratégia configura resposta útil quando os recursos são variáveis e o ambiente incerto.

A estratégia aberta, por meio do processo de interação social que abarca o compartilhamento de crenças e entendimentos, favorece a participação de diversos atores, tanto internos quanto externos, no processo de fazer a estratégia - strategizing, promovendo a transparência não somente do resultado, mas das informações relativas ao processo e, desta forma, favorecendo o compartilhamento de práticas e conhecimento. Nesse sentido, Carrol (2015) afirma que as estratégias de maior sucesso para lidar com a ambiguidade promovem o engajamento de atores internos e externos da organização como forma de promover diversas perspectivas e sugestões inovadoras que contribuam para a aprendizagem.

A aproximação teórica entre a estratégia aberta e as lógicas institucionais é possivel pelo compartilhamento de pressupostos. Assim como as lógicas institucionais, a estratégia aberta assume que a interação social, por meio do compartilhamento de crenças e práticas, constrói a estratégia e a realidade do indivíduo, bem como as próprias crenças e práticas nas quais realiza sua ação.

OS, Organizações e Sustentabilidade, 7(1), p. 16-31, Londrina, PR, jan./jun. 2019.

ISSN 2318-9223, http://www.uel.br/revistas/uel/index.php/ros/issue/view/1535/showToc 
Para ambas as perspectivas, todos os sujeitos ou atores organizacionais são componente ativo na criação de sua realidade e no processo de construção da estratégia e ao longo do tempo mudam sua realidade ao mesmo tempo em que são influenciados por ela. Desta forma, a agência do sujeito - ou da organização - mesmo que limitada pelas lógicas institucionais em que está inserido, ainda o pertence e permite sua decisão e ação perante o cenário complexo em que se encontra.

\section{CONSIDERAÇÕES FINAIS}

0 presente artigo foi pautado pelo argumento de que a abertura da estratégia por meio do engajamento da organização em rede configura uma resposta para a complexidade institucional gerada pelo conflito entre lógicas institucional distintas. Para tanto, o artigo usou como contexto de análise a Rede Empresarial do Pacto Global, criada pela ONU em 2003 com o intuito de ampliar o engajamento das organizações nos compromissos estabelecidos pela ONU para alcance dos Objetivos do Desenvolvimento Sustentável.

Ao aderir ao Pacto Global, a organização declara apoio e assume compromissos com os dez princípios universais relacionados aos direitos humanos, relações de trabalho, meio ambiente e combate à corrupção. Desta forma, é necessária habilidade por parte da organização do setor privado em gerir e responder simultaneamente à demanda da lógica de responsabilidade social e da lógica já presente desde seu surgimento - a lógica de mercado.

A existência dessas duas lógicas conflitantes insere a organização em um contexto de complexidade institucional, considerado pela literatura um fator de incerteza. A incerteza por parte da organização pode ser originada pela falta de conhecimento para ação ou pela ambiguidade dos resultados provocados pela ação. Desta forma, a organização deve buscar uma resposta estratégica para agir e lidar com este contexto.

As redes interorganizacionais podem ser consideradas o contexto para a ação, pois reduzem a incerteza organizacional à medida que promovem o acesso rápido a informações, maior confiabilidade, capacidade de resposta e melhoria na resolução de problemas. Além disso, o engajamento em redes possibilita maior agência por parte da organização em relação à lógica institucional em que está imerso, sendo capaz de revolucionar instituições e iniciar novas ações.

Todavia, as redes por si só não configuram resposta à complexidade organizacional. Neste sentido, a abertura da estratégia se transforma na ação necessária para completar a resposta, pois, assim como as redes, é capaz de reduzir a incerteza e a complexidade institucional por meio da colaboração, envolvimento de todos os atores no processo de construção da estratégia e compartilhamento de informações entre atores internos e externos da organização.

Por meio da literatura foi possivel articular e reiterar o argumento central do artigo, justificando sua relevância prática por tratar de um movimento social relevante que afetará as organizações do setor privado envolvidas no projeto até o cumprimento de sua agenda em 2030. Também caracteriza relevância prática por apresentar a estratégia aberta como resposta para a complexidade institucional de forma diversa ao registrado até então na literatura: por meio da interação social com agentes externos à organização.

0 presente estudo foi limitado por não observar e investigar empiricamente os movimentos estratégicos acima relatados, não sendo possível compreender a sequência e o desdobramento dos fatos que chegaram ao resultado por parte da Rede Brasileira do Pacto Global. Para tanto, é sugerido, enquanto agenda de pesquisa, a observação empírica do argumento teórico, não só em relação ao contexto de análise aqui sugerido, mas também em outros contextos em que a complexidade institucional se faz presente. Não obstante, no contexto de análise específico levantado neste artigo, entende-se como relevante investigar como a homogeneidade da composição da Diretoria da

OS, Organizações e Sustentabilidade, 7(1), p. 16-31, Londrina, PR, jan./jun. 2019. 
Rede e de seu Comitê Gestor pode constituir um campo em que a imersão se configura como fator condicionante da adoção de práticas homogêneas e pouco inovadoras em relação à temática da Responsabilidade Social e a Sustentabilidade, evidenciando um isomorfismo entre as organizações. Não obstante, outro caminho de pesquisa relevante é a investigação da adoção de práticas cerimoniais, dada a homogeneidade encontrada entre todos os membros que fazem parte da rede, em relação à predominância da lógica de negócios na configuração de seu esquema interpretativo. Por fim, entende-se que a discussão delineada neste trabalho merece atenção, principalmente ao considerarmos o contexto cada vez mais urgente em relação à discussão da incomensurabilidade do atual modelo de desenvolvimento de negócios e a sustentabilidade das organizações humanas como hoje se apresentam.

\section{REFERÊNCIAS}

Barney, J. B. (1991). Firm resources and sustained competitive advantage. Journal of Management, 17(1), 99-120.

Battilana, J., \& Dorado, S. (2010). Building sustainable hybrid organizations: The case of commercial microfinance organizations. Academy of Management Journal, 53(6), 1419-40.

Burt, R. S. (2004). Structural holes and good ideas. American Journal of Sociology, 110(2), 349-399.

Carrol, J. S. (2015). Making sense of ambiguity through dialogue and collaborative action. Journal of Contingencies and Crisis Management, 23(2), 59-65.

Dobusch, L., \& Kapeller, J. (2013). Open Strategy between Crowd and Community: Lessons from Wikimedia. Academy of Management Proceedings. 2013(1), 15831-15831.

Emirbyer, M., \& Goodwin, J. (1994). Network analysis, culture and the problem of agency. The American Journal of Sociology, 99(6), 1411-1454.

Friedland, R., Mohr, J.W., Roose, H., \& Gardinali, P. (2014). the institutional logics of love: Measuring intimate life. Theory e Society, 43(3-4), 333-370.

Gast A.; \& Zanini M. (2012) The Social Side of Strategy. McKinsey Quarterly, 82-93.

Granovetter, M. (2007). Ação econômica e estrutura social: O problema da imersão. RAE-eletrônica, $6(1)$.

Greenwood, R., Raynard, M., Kodeih, F., Micellota, R. E., \& Lounsbury, M. (2011). Institutional complexity and organizational responses. The Accademy of Management Annals, 5(1), 317-371.

Haefliger, S.; Monteiro, E.; Foray, D.; \& Krogh, G. (2011). Social Software and Strategy. Long Range Planning. 44(4), 297-316.

Hatch, J. M., \& Ehrlich, B. S. (1993). Spontaneous humour as an indicator of paradox and ambiguity in organizations. Organization Studies, 14(4), 505-526.

Lerner, A. W. (1978). On ambiguity and organizations. Administration \& Society, 10(1), 3-32. 
Meyer, R.E., \& Höllerer, M. A. (2016). Laying a smoke screen: Ambiguity and neutralization as strategic responses to intra-institutional complexity. Strategic Organization, 14(4), 373-406.

Misangyi, V. (2016). Institutional complexity and the meaning of loose coupling: Connecting institutional sayings and (not) doings. Strategic Organization, 14(4), 407-440.

Morton, J., Wilson, A., \& Cooke, L. (2015, July 7). Collaboration and knowledge sharing in open strategy initiatives. Conference Paper Proceedings of iFutures 2015, Sheffield.

Ocasio, W., \& Radoynovska, N. (2016). Strategy and commitments to institutional logics: Organizational heterogeneity in business models and governance. Strategic Organization, 14(4), 287-309.

Oliver, C. (1991). Strategic responses to institutional processes. Academy of Management Review, 16(1),145-79.

Pacto Global. Rede Brasil (n.d.). Histórico. Recuperado em 11 de julho de 2016 de http://www.pactoglobal.org.br/artigo/63/Historico

Pacto Global. Rede Brasil (n.d.). Objetivos. Recuperado em 11 de julho de 2016 de http://www.pactoglobal.org.br/artigo/66/Objetivos

Pacto Global. Rede Brasil (n.d.). Os 10 princípios. Recuperado em 11 de julho de 2016 de http://www.pactoglobal.org.br/artigo/56/0s-10-principios

Pacto Global. Rede Brasil (n.d.). Quem somos. Recuperado em 11 de julho de 2016 de http://www.pactoglobal.org.br/artigo/171/Quem-somos

Powell, W. W. (1990). Neither market nor hierarchy: Network forms of organization. Research in Organizational Behavior, 12, 295-336.

Programa das Nações Unidas para o Desenvolvimento (n.d.). Os Objetivos do Desenvolvimento Sustentável. Recuperado em 11 de julho de 2016 de http://www.pnud.org.br/ODS.aspx

Programa das Nações Unidas para o Desenvolvimento (n.d.). Outras iniciativas. Recuperado em 11 de julho de 2016 de http://www.pnud.org.br/OutrasIniciativas.aspx

Raynard, M. (2016). Deconstructing complexity: Configurations of institutional complexity and structural hybridity. 14(4), 310-335.

Saint-Charles, J., \& Mongeau, P. (2009). Different relationships for coping with ambiguity and uncertainty in organizations. Social Networks, 31(1), 33-39.

Stieger, D., Martzler, K., Chatterjee, S., \& Ladstaetter-Fussenegger, F. (2012). Democratizing strategy: How crowdsourcing can be used for strategy dialogues. California Management Review, 54(4), 44-58.

Tavakoli, A., Schlagwein, D., \& Schoder. D. (2015). Open strategy: Towards a shared understanding. Developmental Workshop on Open Research and Practice in Information Systems. 
Thomasson, A. (2009). Exploring the ambiguity of hybrid organizations: A stakeholder approach. Financial. Accountability \& Management, 25(3), 353-366.

Thorton, H., \& Ocasio. W. (2008). Institutional logics. In R. Greenwood, C. Oliver, R. Suddaby, \& K. Sahlin-Andersson (Eds). The sage handbook of organizational institutionalism. London: Sage.

Thornton, P. H., Ocasio, W., \& Lounsbury, M. (2012). The institutional logics perspective: A new approach to culture, structure, and process. Oxford, England: Oxford University Press.

United Nations - Global Compact. (n.d.). Who we are - our participants. Acessado de https://www.unglobalcompact.org em 15/04/2018.

Vermeulen, P.; Zietsma, C.; \& Langley, A. (2014). Special Issue of Strategic Organization: "Strategic Responses to Institutional Complexity. Strategic Organization. 12(1), 79-82.

Whittington, R., \& Yakis-Douglas, B. (2011). Opening strategy: Evolution of a precarious profession. British Journal of Management, 22(3), 531-544. 